\title{
Formação continuada de professores e resultados dos alunos no SARESP: propostas e realizações
}

Adriana Bauer

Fundação Carlos Chagas

\section{Resumo}

0 presente trabalho apresenta resultados obtidos por meio da pesquisa realizada entre 2005 e 2006, intitulada Uso dos resultados do SARESP: o papel da avaliação nas políticas de formação docente, cujo propósito foi analisar possibilidades e limites da utilização dos resultados obtidos pelos alunos no Sistema de Avaliação do Rendimento Escolar do Estado de São Paulo (SARESP) para a formulação e o direcionamento de políticas de formação de professores. As preocupações recaíram sobre os programas de formação em língua portuguesa para o ensino fundamental. Foram visitadas quatro das treza diretorias regionais de ensino da capital do Estado de São Paulo a fim de conhecer o trabalho de formação docente realizado e analisar em que medida ele se relacionava aos dados obtidos no SARESP. 0 estudo qualitativo teve como principal estratégia a enquete exploratória, com uso de roteiros de entrevista e de observação semiestruturados. 0 referencial teórico sintetizou contribuições de Dennis Palumbo (1998) e de Marcus Figueiredo e Argelina Figueiredo (1986) para a compreensão do conceito e das etapas da política pública, assim como de Elba Barreto e Regina Pinto (2001), Blaine Worthen, James Sanders e Jody Fitzpatrick (2004) e Almerindo Afonso (1998) a respeito da discussão da avaliação de programas, entre outros. Concluiu-se que, apesar de a documentação dos programas de formação e o SARESP declararem que há relação entre os resultados da avaliação e os programas propostos, a concretização desse propósito depende do engajamento dos profissionais presentes nas diretorias de ensino. As ações formais da Secretaria da Educação para induzir esse uso de resultados não se mostraram suficientes para assegurar o pretenso vínculo entre avaliação e formação docente.

\section{Palavras-chave}

SARESP - Formação de professores - Avaliação de políticas educacionais.
Correspondência: Adriana Bauer

Fundação Carlos Chagas Rua Quitantuba, 363 05516-030 - Caxingui/SP dri_bauer@yahoo.com.br 


\section{Teacher continued education and the results of pupils in the SARESP exam: proposals and achievements}

Adriana Bauer

Carlos Chagas Foudation

Contact:

Adriana Bauer

Fundação Carlos Chagas

Rua Quitantuba, 363

05516-030 - Caxingui/SP

dri_bauer@yahoo.com.br

\section{Abstract}

This work presents results of a study conducted between 2005 and 2006 entitled The use of the results of the SARESP Exam: the role of assessment in teacher education policies (Uso dos resultados do SARESP: o papel da avaliação nas políticas de formação docente), whose purpose was to analyze possibilities and limits of the use of the results obtained by pupils in the SARESP Exam (School Performance Assessment System of the State São Paulo) to formulate and direct teacher education policies. The attention was focused on education programs for teachers of Portuguese Language to pupils in fundamental education. Four out of the thirteen Regional Education Directorships of the State of São Paulo were visited to gain acquaintance with the teacher education programs they developed and to investigate to what extent they could be related to the results achieved in the SARESP exam. The qualitative study adopted as its main strategy the exploratory survey, with the use of semi-structured interview and observation scripts. The theoretical framework employed brought together contributions by Dennis Palumbo (1998) and Marcus Figueiredo and Argelina Figueiredo (1986) to understand the concept and stages of public policy, as well as by Elba Barreto and Regina Pinto (2001), Blaine Worthen, James Sanders and Jody Fitzpatrick (2004), and by Almerindo Afonso (1998) on the discussion about assessment programs, among others. It concludes that, the statements in the teacher education program and in the SARESP documentations about the correlation between the former and pupil assessment results notwithstanding, the actual achievement of positive results depends on the effective commitment of the professionals working at the Education Directorships. Formal actions by the Secretariat for Education to foster this use of the results have proved insufficient to ensure the proposed link between pupil assessment and teacher education.

\section{Keywords}

SARESP - Teacher education - Evaluation of education policies. 


\section{Usos dos resultados de avaliações dos alunos na definição de programas de educação continuada de professores: a experiência de São Paulo}

A avaliação de sistemas educacionais vem-se intensificando desde a década de 1990, tornando-se um ponto de destaque nas propostas de políticas públicas ligadas à educação, não só no Brasil, mas em diversos países. Esse fenômeno, que autores como Almerindo Afonso (1998) e José Dias Sobrinho (2002) relacionam à mudança do papel do Estado na educação e às necessidades de melhor gerenciamento dos recursos disponíveis e de diagnóstico para a melhoria do ensino público, tem feito com que a avaliação ocupe papel de destaque nas políticas públicas educacionais.

0 poder executivo do Estado de São Paulo, nas gestões de Mário Covas e Geraldo Alckmin (1995-2006), delegou à avaliação um papel de destaque nas políticas educacionais.

Por meio da leitura de documentos ofıciais sobre a implantação da avaliação no Estado de São Paulo ${ }^{1}$, constata-se que o Sistema de Avaliação do Rendimento Escolar do Estado de São Paulo (SARESP) foi apresentado como uma iniciativa importante, inserida em um projeto político mais ousado dos gestores da rede de revisão e modificação do sistema educacional público paulista. Segundo a equipe educacional do governo da época, liderada por Rose Neubauer, o sistema estadual precisava de reformas urgentes, já que os serviços oferecidos não eram de qualidade e a gestão não ocorria de forma eficiente:

A década de 70, apesar de presenciar um grande crescimento do sistema educacional do Estado, não se preocupou com a qualidade do ensino ofertado [...]. Observa-se,

1- Nesse sentido, ver o Comunicado SE de 22 de março de 1995 (Diretrizes Educacionais para o Estado de São Paulo) e o documento de implantação do SARESP, cuja referência completa está indicada na bibliografia. no entanto, que a educação pública paulista permaneceu não só caótica como, também, desorganizada. De fato, a Secretaria da Educação nunca se propôs a implantar um sistema eficiente de gerenciamento das unidades escolares, que lhe permitisse conhecer a real situação em que estas se encontram. Dessa forma, não há como nelas intervir, perpetuando-se um sistema ineficiente e altamente centralizado, onde a deterioração da qualidade do ensino alia-se àquela de sua rede física. (SÃO PAULOa, 1995)

Oficialmente, difundiam-se vários objetivos para a avaliação paulista. Um desses objetivos, anunciado em um dos documentos do SARESP denominado Manual do Orientador de 1998, assumiu particular interesse no âmbito desta pesquisa:

o SARESP foi criado com a intenção de gerar uma cultura de avaliação que agilizasse tomadas de decisão de melhoria e incrementasse a capacitação contínua de todos os educadores e demais profissionais envolvidos no sistema. (SÃO PAULOb, 1998, p. 1; grifos nossos)

Em outros documentos divulgados pela equipe da Secretaria de Estado da Educação de São Paulo (SEE/SP), há afırmações que reiteram tal propósito, como a seguinte:

Os resultados da avaliação, devidamente levados em conta, podem indicar caminhos para as atividades de capacitação propostas pelos órgãos centrais ou pelas DE para serem desenvolvidas junto às escolas [...]. (BITTAR et al., 1998, p. 12; grifos nossos)

A investigação de afirmações dessa natureza constituiu o cerne da pesquisa ora relatada, cujo objeto foi analisar se os resultados do SARESP estavam sendo utilizados para indicar caminhos para as atividades de capacitação ${ }^{2}$ docente.

2- 0 conceito de capacitação, como apontam alguns autores, carrega a ideia de que 0 professor precisa ser capacitado para sua atividade pro- 


\section{O problema e a metodologia de pesquisa}

0 problema de pesquisa foi examinar se os resultados do SARESP apoiavam as ações de formação. Caso os dados obtidos apontassem para uma resposta positiva a essa questão, procurar-se-ia responder para quê e como ocorria essa utilização. Além disso, buscou-se verificar de que modo os profissionais responsáveis pela formação entendiam a relação entre a avaliação e a formação de professores.

Para proceder à análise, a pesquisadora apostou em uma metodologia qualitativa, enfatizando o uso da enquete, entendida aqui como

estratégia de pesquisa que visa determinar o quadro geral de uma situação, apoiando-se em dados obtidos de fontes diversas com o auxílio de diferentes instrumentos. (LAVILLE; DIONNE, 1999, p. 151)

A investigação foi desenvolvida entre os anos de 2005 e $2006^{3}$, tendo como base depoimentos de técnicos da SEE/SP, bem como de supervisores de ensino e assistentes técnico-pedagógicos dessa rede. Foram realizadas quatorze entrevistas com profissionais de diretorias de ensino, duas com técnicos em avaliação da Fundação para o Desenvolvimento da Educação (FDE) e uma na Coordenadoria de Estudos e Normas Pedagógicas (CENP). Tais órgãos foram escolhidos para evidenciar posições da Secretaria da Educação no que se refere à relação entre

fissional. Acreditamos que o conceito que melhor expressa as necessidades formativas dos professores é 0 de desenvolvimento profissional, que se adapta ao entendimento do professor como profissional da educação, abarcando também uma conotação de evolução e continuidade que supera a tradicional justaposição entre formação inicial e aperfeiçoamento de professores (GARCIA, 1999). Contudo, durante a exposição, serão usadas as expressões encontradas com mais frequência nos textos analisados, ou seja, capacitação e formação continuada, pois elas possuem uma carga ideológica que não é desprezível.

3- As considerações realizadas neste artigo, portanto, são traçadas a partir das informações obtidas nos anos da pesquisa. Ao leitor, contudo, deve estar claro que o processo de implementação de políticas e programas educacionais é dinâmico, e que podem ter ocorrido, desde então, modificações na sistemática de avaliação e divulgação de resultados, bem como em seu uso. avaliação de sistemas educacionais e formação docente. Também foi possível entrevistar um coordenador pedagógico e alguns professores de ciclo 1 durante uma visita realizada a uma escola de ensino fundamental I para o acompanhamento da aplicação do SARESP.

0 presente texto focaliza suas considerações nas atividades de formação realizadas pelos assistentes técnico-pedagógicos (ATPs) e pelos supervisores de ensino ${ }^{4}$ (organização de cursos e atividades similares para as escolas), e em seu entendimento da relação entre o SARESP e a formação de professores. Buscou-se explicitar a importância que atribuem, em suas falas, à discussão dos resultados da avaliação, bem como a disponibilidade que demonstram para incorporar esses resultados à sua prática profissional. Tais agentes são considerados essenciais para a concretização da proposta de relacionar resultados da avaliação às ações de formação docente, pois são, no nível intermediário entre a Secretaria da Educação e as escolas, os responsáveis pela formação dos professores (em especial, os ATPs) e pelo acompanhamento do trabalho das escolas (notadamente, os supervisores de ensino).

\section{Tendências na avaliação de políticas públicas}

Dennis Palumbo (1998) identifica três formas de se fazer estudos sobre políticas: a análise das políticas, sua implementação e a avaliação de programas ${ }^{5}$.

4- A pesquisa original (BAUER, 2006) foi mais abrangente, incluindo depoimentos de agentes da Fundação para o Desenvolvimento da Educação (FDE) e da Coordenadoria de Estudos e Normas Pedagógicas (CENP). 0 presente artigo enfoca, contudo, os discursos dos ATPs e dos supervisores. 5- Palumbo faz uma breve descrição de cada uma dessas formas. Segundo ele, a análise de políticas "geralmente acontece antes de se tomar as decisões sobre uma determinada política. Seu principal objetivo é encontrar a forma mais eficiente de maximizar as metas e os objetivos". Já a implementação das políticas "focaliza basicamente o processo pelo qual as políticas são traduzidas em programas e como eles são administrados e gerenciados". Finalmente, a avaliação de programas é "basicamente uma atividade pós-decisória que visa determinar se um programa está alcançando suas metas, o que o programa está realizando" (PALUMBO, 1998, p. 57-58). Não é objetivo deste trabalho aprofundar na temática da análise das políticas. Fica registrado, contudo, que, na prática, acreditamos que essas etapas deveriam ser intercambiáveis, em um movimento cíclico e dialógico. 
Observa-se que os estudos sobre politicas que começaram a desenvolver-se na década de 1940, no contexto norte-americano, concentravam-se na análise da politica e das estratégias utilizadas para sua execução, ou seja, de sua implementação, com o objetivo de auxiliar as organizações governamentais a aprimorarem suas metas e de, portanto, maximizar a ação da política. Também em um viés mais econômico, a análise política dedicou-se a planejar e preparar orçamentos para as agências governamentais, a fım de subsidiar a realização e a continuidade da política. A ênfase, então, recaía na análise da política e do processo, não havendo forte preocupação com a avaliação dos resultados em seu sentido mais estrito.

De fato, o que se observava em relação às políticas públicas e mais estritamente àquelas relacionados ao campo educacional é que os programas, ações e reformas sucediam-se sem que fosse feita uma avaliação isenta e fundamentada sobre sua eficiência e possíveis impactos. Muitas vezes, não era realizada sequer uma análise da política e de sua execução, sendo que a base para a tomada de decisão comumente eram as experiências já realizadas ou, ainda, o apoio financeiro e político que seria obtido para dado programa.

No que se refere à produção de conhecimento teórico na área, essa tradição vem modificando-se desde a década de 1960, principalmente devido à influência da produção teórica estadunidense. Naquele país, pressões sociais e o surgimento de novas tendências políticas apontaram a necessidade de que as decisões políticas fossem mais racionalizadas e de que as ações realizadas fossem mais eficientes e concordes com os desejos da população, além de menos dispendiosas, havendo uma ênfase nas discussões sobre avaliação de programas (WORTHEN; SANDERS; FITZPATRICK, 2004; WHOLEY, 2004).

Desde os anos 1980, os estudos sobre as políticas públicas intensificaram-se e passaram a constituir um campo de investigação específico (FIGUEIREDO; FIGUEIRED0, 1986), e as ações governamentais passaram a ser avaliadas, inclusive, pelas próprias administrações que as propunham (BARRET0; PINTO, 2001).

Cabe, no entanto, abrir um parêntese para frisar que essa não é ainda, pelo menos no Brasil, uma tendência fortemente arraigada entre as instituições governamentais, pois, como explicita Palumbo (1998),

a reflexão nem sempre precede uma ação; comumente, um indivíduo ou uma agência governamental age primeiro e depois analisa o que foi feito. (p. 59)

No caso do Brasil, observa-se que, apesar de os estudiosos apontarem para um maior desenvolvimento da na avaliação de políticas, não há consensos sobre alguns conceitos específicos da área, tampouco sobre os quadros de referência teórica da temática, fato que gera dificuldades para o pesquisador que pretende dedicar-se a esse tipo de trabalho. Como explicitam Elba Barreto e Regina Pinto (2001),

há uma série de dificuldades conceituais para delimitar o campo de análise das políticas públicas, bem como o de sua avaliação propriamente dita, visto que os referentes teóricos que lhes servem de base ainda não estão fortemente consolidados. (p. 104)

$\mathrm{Na}$ verdade, conforme comentam elas, poucas são as publicações destinadas à temática da avaliação de programas e políticas - ou pesquisa de avaliação - em âmbito nacional, sendo que estas normalmente se encontram no meio acadêmico (notadamente, em teses e dissertações) e apenas algumas se desenvolvem em agências especializadas, a pedido das próprias administrações.

Tal carência, aliada à necessidade de contribuir para a discussão metodológica em avaliação de políticas públicas educacionais, é o principal motivador para a difusão dos resultados da pesquisa realizada em 2006 pela autora, que espelha o esforço de fazer uma 
avaliação mais formal e sistemática do alcance dos resultados anunciados no desenho de uma política educacional.

\section{Questões conceituais relacionadas à avaliação de políticas e de sua implementação}

Tomando como referência o trabalho de Palumbo (1998), considera-se que uma política não é algo palpável, objetivo e, portanto, de fácil apreensão. Por estar em constante mutação e envolver vários agentes, em diversos níveis, uma política muitas vezes tem que ser inferida pelas ações que são traçadas para sua execução e pelo comportamento dos que são encarregados de sua elaboração e aplicação. Essas ações e comportamentos, assim como as leis, os regulamentos e os documentos elaborados, são apenas alguns elementos indicativos do que é a política. 0 autor chama a atenção para o fato de que esses elementos, isolados, não constituem a política, pois parte da concepção de que

uma política pública, assim como a política partidária é complexa, invisível e elusiva [...] e não é algo que possa ser identificado, considerando-se um único evento ou uma única decisão. (p. 35)

Assim, analisar uma política, tendo em vista que esta não é algo objetivo que possa ser apreendido a partir de alguns elementos, implica ter clareza de que as conclusões tiradas estarão estreitamente relacionadas ao olhar do pesquisador que toma tal tarefa para si. Esse é um primeiro pressuposto a ser considerado. Ou seja, a análise a ser realizada a respeito de um dos projetos que fazem parte da política educacional do Estado de São Paulo procurará levar em conta que as declarações presentes nos documentos oficiais dos programas analisados são apenas indícios da política mais ampla. Portanto, as inferências realizadas a partir dos indícios são bastante particulares, tendo em vista as lentes teóricas utilizadas pela pesquisadora.
Um segundo pressuposto é que uma política nem sempre é implementada de acordo com seu desenho original, uma vez que muitos fatores influenciam no processo de execução, principalmente as concepções e crenças dos diversos agentes responsáveis pela implementação. Assim, nem todos os fatores que influenciam a execução da política podem ser controlados ou antecipados no momento de sua formulação.

Nesse sentido, deve-se levar em conta que são diversos os elementos que influenciam a formulação e também a implementação de políticas públicas. Eles vão desde a afinidade política dos agentes, que executam o programa conforme seus princípios e diretrizes, até a escolha de estratégias de implementação (muitas vezes, influenciadas pela possibilidade de aceitação dos agentes e do público que irá beneficiar-se da política).

Considerando-se que, no caso do objeto analisado, os agentes das diretorias de ensino são responsáveis por concretizar a política, pretendeu-se verificar se estes conheciam os objetivos do SARESP em sua articulação com os programas de formação docente, bem como analisar sua apreciação sobre os programas de avaliação (SARESP) e de formação.

Finalmente, as condições de implementação e continuidade dos projetos em análise foram observadas e confrontadas com os objetivos e ações apontados nos documentos oficiais. Contudo, considerou-se que, muitas vezes, os objetivos iniciais traçados para determinado programa educacional podem modificar-se ao longo do período de sua vigência, sendo fundamental contemplar essas mudanças no momento da avaliação. Mais do que uma comparação direta entre o previsto e o realizado, procurou-se levantar informações que pudessem auxiliar a vislumbrar os aspectos que intervêm na concretização da política. Eis o terceiro pressuposto considerado nesta pesquisa. 


\section{SARESP e programas de} formação

Um dos indicadores utilizados para a análise da relação entre os resultados das avaliações e as necessidades de formação dos professores foi a própria opinião expressa pelos entrevistados sobre esse vínculo e sobre como os resultados da prova poderiam ser utilizados para iluminar as atividades de formação.

\section{a) A articulação entre SARESP e formação: discurso} ou realidade?

A análise das entrevistas em relação a este aspecto permite ponderar que, tendencialmente, os profissionais entrevistados apresentaram um discurso concordante com os documentos oficiais da Secretaria da Educação, salientando a importância do SARESP para a definição de políticas públicas educacionais no Estado:

Quando eles [a Secretaria da Educação] fazem a avaliação externa, que é essa avaliação grande, o SARESP, o que acontece é que lá em cima [nivel central] vai ter uma amostra de tudo isso e é a partir dela que eles vão focando o restante dos projetos, como o Terra Paulista, por exemplo, em que trabalham coisas que eles vão percebendo na avaliação externa. Eles vão tentando dar os projetos, mostrar mesmo em termos de conhecimento, ver os vestibulares, ver o que está acontecendo com os alunos e, assim, vão tentando direcionar as coisas (Dirigente Regional de Ensino, D. E. Alfa ${ }^{6}$; grifos nossos)

6- Todos os nomes das diretorias de ensino visitadas são fictícios, a fim de preservar as diversas instituições envolvidas na pesquisa. Procurou-se, também, garantir 0 anonimato dos profissionais que foram entrevistados, sendo eles identificados somente pela função que exercem, dado fundamental para compreensão e contextualização de suas falas. Neste artigo, os depoimentos obtidos durante a pesquisa são parcialmente reproduzidos e foram, quase sempre, gravados e transcritos ipsis literis, exceção feita quando 0 entrevistado não permitiu a gravação. Contudo, caso o leitor se interesse pelos depoimentos na íntegra, poderá encontrá-los no endereço
O Estado, em cima das avaliações que faz, as avaliações externas como SARESP e ENEM, que estão subsidiando todo o projeto de ensino médio, e outras avaliações que o governo faz, orienta as politicas públicas e de formação de professores. [...]. Todos os projetos da Secretaria são escolhidos e realizados a partir das necessidades que a rede apresenta [...]. E a avaliação que fizeram de matemática vai estar por trás de todo o investimento que vão fazer agora em matemática. (ATP de língua portuguesa do ciclo 1, D. E. Beta; grifos nossos)

Há uma ligação entre os resultados obtidos nas avaliações externas e a formação em serviço oferecida aos professores da Diretoria de Ensino Ômicron. É a partir desses indicadores que são montadas as Orientações Técnicas, aquisição de cursos junto às Universidades. (Dirigente Regional de Ensino, D. E. Ômicron; grifos nossos)

Os programas que eles implantaram a partir do SARESP foram: Tecendo Leituras, o Hora da Leitura, o Escrevendo o Futuro, o Ler e Viver e o Ensino Médio em Rede. Todos eles a partir desses resultados. (Coordenadora da Oficina Pedagógica ${ }^{7}$, D. E. Delta; grifos nossos)

Da forma como os técnicos das diretorias visitadas afirmaram, parecia que os resultados do SARESP estavam subsidiando os programas de capacitação docente, indo ao âmago das necessidades formativas dos professores, quer na capacitação para o entendimento dos resultados do SARESP, quer na formulação de ações que incidiriam diretamente sobre os pontos fracos ou problemas revelados pelo rendimento apresentado nas provas.

eletrônico <http://www.teses.usp.br/teses/disponiveis/48/48134/tde06032008-110423/>, no arquivo intitulado Anexos.

7-A oficina pedagógica é composta por assistentes técnico-pedagógicos e funciona em cada diretoria regional de ensino. Sua principal atribuição é a prestação de assistência e apoio técnico-pedagógico às unidades escolares (tanto ao corpo docente, quanto ao técnico-administrativo). 
Assim, ao analisar as respostas obtidas, percebe-se que a ideia de que a avaliação externa servia para subsidiar a formação docente permeava o discurso de muitos dos profissionais entrevistados.

Entretanto, nesses depoimentos, não foram oferecidos indícios que mostrassem essa relação, ou seja, havia uma grande aceitação do discurso oficial, inferida a partir de expressões como eles sabem, a partir dos resultados, está subsidiando etc., sem que fossem oferecidas evidências que explicitassem uma relação mais direta entre a avaliação de rendimento do aluno e o desempenho docente. Também não foram obtidas explicações que possibilitassem apreender como eram detectadas as necessidades dos professores e como os resultados eram traduzidos em propostas de formação ${ }^{8}$.

Diante da indagação sobre a existência de indícios que comprovassem o vínculo entre as ações citadas e os resultados da avaliação, em geral, os entrevistados não forneceram exemplos que esclarecessem tal articulação.

$\mathrm{AB}^{9}$ : Se a Diretoria está vendo uma recorrência nos dados, tem como planejar uma ação para ir "direto ao ponto", uma formação que ela ache que vai atender um determinado grupo de professores. Como ocorre essa relação?

CA: Nós temos detectado assim que há... Que os professores saem das universidades com muitas falhas, com muitas deficiências. Então, no decorrer do ano, nós trabalhamos com Orientações Técnicas... Seriam palestras, cursos práticos para esses professores, proporcionados pela Oficina Pedagógica para sanar exatamente essas dificuldades, para trocar ideias, ver o que eles podem trabalhar de forma melhor com seus alunos, com mudanças de ativida-

8- A relação entre prática docente e resultados dos alunos, como explorada em um dos capítulos da dissertação dedicada à pesquisa, não está dada e permanece controversa entre autores e estudiosos das áreas de formação docente, avaliação educacional e eficácia escolar (para maiores referências, ver BAUER, 2006).

9- Referência às iniciais da pesquisadora. des, novas metodologias de trabalho, atividades diversificadas... A gente vai treinando os professores, né...

$\mathrm{AB}$ : Mas como são definidos os conteúdos a serem trabalhados no projeto Teia do Saber, no projeto do Ensino Médio... Como que é possível saber que é aquilo que o professor está precisando?

CA: Exatamente com os dados que eles obtêm através do SARESP... Eles trabalham... Eles sabem quais são os pontos em que há maior dificuldade por parte dos professores. (Supervisor de Ensino / Coordenador do SARESP, D. E. Alfa; grifos nossos)

Nós temos o acompanhamento de tudo isso através de nossos supervisores que visitam as escolas. E através das Oficinas Pedagógicas, que produzem gráficos. Também sabemos através do retorno da própria escola para a Diretoria de Ensino. Aqui desenvolvemos um trabalho pedagógico onde, a cada bimestre, a escola tem que dar um retorno para a Oficina Pedagógica. [...] Dessa forma poderemos ver onde está o problema. (Dirigente Regional de Ensino, D. E. Alfa; grifos nossos) $)^{10}$

SARESP era um indicador. Tanto que, no começo, o SARESP era nas séries terminais, e quando chegava [dava para perceber] que um dos pontos de estrangulamento era da quarta série a oitava. Foi detectado grande número de alunos, tanto na quarta quanto na oitava que não tinham o domínio da leitura e da escrita, e a partir de 2003 começou a ser toda a rede. E a gente faz um acompanhamento. De como estava essa turma de 2003 e como foi o desempenho de 2004 e 2005 e isso reverte tudo em políticas públicas. (ATP de língua portuguesa do ciclo 1, D. E. Beta; grifos nossos)

10- 0 leitor deve notar que, neste depoimento de uma dirigente regional, entre os exemplos citados sobre como as atividades de formação são definidas, não há referência à avaliação estadual, o que contradiz 0 depoimento anterior dado pelo supervisor da mesma Diretoria. 
Fez a prova, diagnosticou os problemas? Vamos capacitar em cima daqueles problemas, dar soluções para aquilo. E o professor vai trabalhar recebendo essas orientações para estar ajudando seus alunos. (Dirigente Regional de Ensino, D. E. Delta; grifos nossos)

Mesmo que alguns depoimentos reafirmassem a intenção encontrada nos documentos ofıciais e no discurso de representantes da Secretaria da Educação de relacionar avaliação e programas de formação, observou-se que as iniciativas de formação citadas pelos entrevistados não ilustravam essa articulação. Nesse sentido, é possível afirmar que nem sempre os argumentos utilizados para ilustrar a estreita relação entre SARESP e formação docente eram adequados e se sustentavam, permitindo que se questione se tais propostas não poderiam ser realizadas mesmo sem a existência do SARESP.

Um exemplo do exposto é dado pela fala do dirigente de ensino da Diretoria Delta, ao enfatizar ações formativas estabelecidas em parcerias com empresas, em áreas não diretamente relacionadas ao ensino de língua portuguesa:

Nesse ano temos, por exemplo, o "Letra e Vida”. Outros projetos que a Secretaria também tem para quinta e oitava séries são "Os Números em Ação", que é o reforço matemático e na informática. Nós tivemos o "Trilhas e Letras", que é da quinta à oitava série e também é voltado para a Língua Portuguesa. E muitos outros... Mas devo lembrar não só dos projetos da Secretaria [...] E a gente aqui trabalha com parcerias: nós temos muita parceria mesmo: tem o projeto "Cinema e Vídeo Brasileiro", em que já estamos indo para o quarto ano, que é para trabalhar a linguagem do cinema. Temos um programa de educação afetiva e sexual, onde já estamos no quarto módulo de capacitação. Trabalhamos com o Instituto Sou da Paz na questão dos crimes estudantis. Temos um projeto de papel.
A gente trabalha com a polícia militar... Então é um conjunto de ações que vão fazendo com que a escola se transforme, né? (Dirigente Regional de Ensino, D. E. Delta; grifos nossos)

Evidencia-se, assim, que há uma avaliação das necessidades de formação docente, talvez feita de forma informal pelos técnicos da Diretoria de Ensino, que passa ao largo das indicações do SARESP.

Explica, ainda, que o trabalho de formação não se limita aos cursos de formação da Secretaria, sendo que a Diretoria promove suas próprias ações para a formação. Segundo ela, essas ações são de dois tipos: acompanhamento dos cursos da Secretaria e Orientações

Técnicas para o trabalho docente, elaboradas pela Oficina para os professores das diversas áreas. Essas Orientações Técnicas, são propostas a partir das necessidades dos professores, mas também, segundo a entrevistada, sofrem influência das preferências do ATP em cada área. Há, contudo, uma preocupação em relacionar tais ações àquelas que são elaboradas em nível central. Essa, no entanto, é uma das organizações possíveis, sendo que na DE Ômicrom foi combinando esses tipos de ação.

Quando perguntei sobre sua opinião sobre para que serviriam, então, os resultados do SARESP, a ATP explicou que acha que a avaliação é um importante diagnóstico, que pode nortear tanto as questões da política educacional, quanto seu trabalho mais específico, na Oficina Pedagógica. Ela afirma, contudo, que continuaria fazendo diagnósticos sobre as necessidades dos professores mesmo sem a prova. (trecho do diário de campo da pesquisadora sobre entrevista com ATP de língua portuguesa, D. E. Ômicron; grifos nossos) 
Em uma análise geral dos excertos dos depoimentos, parece que os entrevistados partem do pressuposto de que citar o SARESP como instrumento definidor das necessidades de formação do professor é um processo racional e legítimo de gestão das prioridades educacionais. Além disso, observa-se que em nenhum momento houve um questionamento sobre a possibilidade de os resultados do desempenho, em um determinado conteúdo, respaldarem ações que tematizassem esse conteúdo com os professores.

Ao que parece, no entanto, a ideia de que as dificuldades dos professores em ensinar certos conteúdos, diagnosticadas a partir do desempenho dos alunos, devem ser tematizadas e de que, após tal trabalho, os índices de desempenho dos alunos automaticamente melhoram é uma crença bastante generalizada entre os entrevistados. Cabe lembrar, contudo, que a relação entre os resultados de desempenho dos alunos e a formação docente não está dada, como explicita o Prof. Heraldo Vianna (2003):

A avaliação - sempre considerando o caso brasileiro - procura, igualmente, estabelecer a eficiência do sistema, avaliando, indiretamente, o êxito da ação docente dos professores. [...] Avaliar o professor é sempre tarefa difícil e ingrata, mas deve ser feita, desde que com competência e, sobretudo, bom senso. A avaliação indireta, por meio do desempenho dos alunos, por sua vez, representa grande risco, com amplas conseqüências. É evidente que o processo ensino/aprendizagem se realiza por intermédio da interação professor/aluno, mas, por si, essa interação não resolve inteiramente a questão. Fatores externos à escola, inteiramente conhecidos pelos que transitam no mundo da pesquisa educacional, também têm importante papel no sucesso escolar [...]. o fracasso ou o baixo desempenho numa avaliação, portanto, nem sempre está relacionado ao professor, que, muitas vezes, por si, não tem condições de atuar visando à eliminação desses fatores. (p. 11; grifos nossos)
Nesse sentido, apenas propor ações de formação docente em áreas e conteúdos nos quais os alunos não foram bem-sucedidos em avaliações em larga escala desconsidera outras variáveis que intervêm no desempenho dos alunos e que, muitas vezes, estão fora do escopo da escola, como as variáveis socioeconômicas e culturais.

\section{b) 0 SARESP como indicador para ações de formação elaboradas nas diretorias de ensino}

No que se refere ao preparo das ações de formação pela própria equipe das diretorias e às reais necessidades de formação dos professores, os técnicos forneceram depoimentos bastante controversos.

Em nível de Diretoria, essa formação continuada, por exemplo, nós temos alguns cursos para educação especial, o curso de Libras. Às vezes a Secretaria, às vezes é um projeto que a Diretoria faz, isso vai para a CENP, se a CENP homologar, esse ano nós tivemos até subsídio financeiro para levar os projetos. (ATP de língua portuguesa do ciclo 1, D. E. Beta)

CA: Deveria ser possível fazer uma opção [pelos cursos oferecidos pela Secretaria de Educação] de acordo com seu Plano, de acordo com seus diagnósticos, seria definida a necessidade de cada escola. Seu problema é a matemática? Então vá ao curso de matemática. [...] A Diretoria, ultimamente, só está atendendo esses projetos, da Secretaria. Não tem como ela fazer [atividades de formação] fora. A gente até tem alguns projetos fora, mas ela fica mais com a incumbência de cumprir os projetos que já vem da rede. Não tem mais assim... da Diretoria poder decidir... Teve uma época que a gente podia pedir uma verba e a gente fazer nossos próprios cursos, mas agora ficou mais nesses cursos da Secretaria mesmo. [...] Então eram cursos 
que você montava de acordo com a necessidade da sua Diretoria. [...] Eu acho que deveria ser ao contrário. Se você pega e coloca o SARESP como o objetivo, a partir dai a Diretoria deveria poder elaborar o seu plano de ação em cima das suas dificuldades. E aí descentralizar. Ter alguns projetos pela rede e se houvesse necessidade a gente escolheria de acordo com as propostas e algumas coisas que a gente pudesse fazer... (Supervisora de Ensino / Coordenadora do SARESP, D. E. Delta; grifos nossos)

Embora o discurso da Secretaria da Educação enfatize a existência de muitos projetos e a possibilidade de a Diretoria de Ensino realizar seus cursos a partir do estabelecimento das prioridades que o SARESP auxilia a definir, percebe-se uma obrigatoriedade em acompanhar as atividades de formação propostas pela Secretaria, o que deixa pouco espaço para a Diretoria realizar suas próprias atividades de formação.

Não! Não. A Diretoria recebe os projetos que a Secretaria quer implementar, e ela tem que implementar! Não há escolha. A escola tem projetos que ela deve implementar; projetos que ela pode optar ou não, tá? Então, para a escola há uma gama diferente de possibilidades. Para a Diretoria não, nós temos que implementar todos os projetos. Nós temos que oferecer todos os projetos. [...]. A pressão é que ele se veja sem saída e faça [o curso]. Ele tem que ser pressionado: o bônus é maior para quem faz o "Letra e Vida", existe uma série de pressões muito sutis que a Secretaria faz. 0 "Letra e Vida" é o que tem a maior carga horária para progressão. (ATP de língua portuguesa do ciclo 1, D. E. Beta; grifos nossos)

Observa-se que, apesar de o discurso oficial trabalhar com uma estrutura de formação dividida em ações centralizadas e descentralizadas, pode-se inferir que há um controle, pela
Secretaria, das propostas locais que, em tese, deveriam atender às especificidades de cada escola, de cada Diretoria.

Outra dificuldade apontada é que a oficina pedagógica tem que acompanhar todos os cursos propostos pela Secretaria, sobrando pouco tempo para que os profissionais que nela atuam possam fazer propostas próprias a partir do diagnóstico das necessidades dos professores a que atendem.

Sendo assim, ao chegar à Diretoria, a professora percebeu uma aparente mudança na concepção sobre as tarefas do ATP, que passou de elaborador de atividades para executor de atividades formuladas pela CENP, tendo se decepcionado um pouco no sentido de suas novas atribuições, já que tal concepção limitou um pouco o trabalho de criação que, antes, era inerente à função. A professora deixou claro que ainda existe a possibilidade dos ATPs fazerem um trabalho mais relacionado ao cotidiano das escolas, mas como houve um boom de projetos da Secretaria, notadamente nos últimos dois anos (atualmente são 126 ao todo), sobra pouco tempo para que outros projetos sejam elaborados. [...] Perguntada sobre a possibilidade de utilizar os resultados do SARESP para embasar os projetos das escolas e dar apoio ao professor, a professora enfatizou que, atualmente, os resultados do SARESP não são analisados na Oficina, sendo que, desde sua chegada só tomou conhecimento de um trabalho da OP sobre o SARESP: a análise das amostras de redações, principalmente no que se refere à utilização adequada dos critérios de correção. Dessa forma, desde sua chegada à Diretoria, a avaliação dos resultados, pelo menos os do Ciclo 2 do Ensino Fundamental e os de Ensino Médio, não passou pela Oficina. (trecho do diário de campo da pesquisadora sobre entrevista com ATP de língua portuguesa, D. E. Alfa; grifos nossos) 
Em algumas diretorias, indicou-se que seria interessante a possibilidade de completar o trabalho de formação realizado pela Secretaria da Educação, considerando-se as especificidades e necessidades de formação dos professores da região que, muitas vezes, não são atendidos pelos cursos ministrados.

E o pessoal reclamou muito da qualidade do curso, porque este da [Universidade X] a gente tem professor aqui... $\mathrm{E}$ aí que eu te falo que os professores da rede particular subestimam, não sei se eu posso usar essa palavra, ou não conhecem a realidade do professor da escola estadual, não vou colocar toda a escola pública, porque a municipal eu não conheço bem. Os professores foram na abertura um dia lá e vierem na segunda-feira correndo, para desistir, que não iam ter paciência para aguentar este curso... E não pode desistir e a gente queria saber o porquê... Qual a justificativa... E eles disseram o seguinte: fulano é um professor da rede municipal, trabalha na sala de leitura, fora de sala de aula e ainda vai dar o curso Teia do Saber, para nós, professores de Português... Elas estavam indignadas, sabe? (ATP de língua portuguesa, D.

E. Beta; grifos nossos)

É necessário considerar, ainda, que a realidade observada sugere que nem todas as diretorias visitadas realizavam as ações previstas ou sugeridas pela Secretaria nos documentos dos programas, elaborando ações próprias a partir dos resultados ${ }^{11}$. De modo dominante, percebe-se que a proposição de ações de formação, baseadas nos resultados do sistema de avaliação estudado, fica na dependência da disponibilidade do pessoal técnico alocado em cada Diretoria.

11- Um dos problemas para essa utilização dos dados refere-se à sua divulgação e à capacidade do pessoal técnico das diretorias em analisar e compreender os dados a fim de propor ações baseadas neles. Tal questão já foi explorada em trabalhos anteriores e, portanto, não será retomada neste artigo (para maiores informações sobre esse assunto, consultar BAUER, 2006, 2008).
Vale ressaltar que a diretriz da Secretaria é de que as diretorias de ensino elaborem uma proposta de ação que deve estar baseada nos dados da avaliação, além de sistematizada e incorporada aos planos diretores da Diretoria de Ensino.

- Leitura e interpretação do desempenho do Estado, da DE, da Escola pela equipe da escola.

- Listar as habilidades da U.E. com maior e menor índice de acertos por série/ período, analisar os gráficos e os resultados.

- Proposição de ações pela equipe gestora e professores frente à análise dos dados de desempenho da U.E.

- Adequação do Plano de Ensino (professor) face às dificuldades detectadas e às mudanças na prática metodológica.

- Anexar, ao Plano de Ensino, cópia das reformulações necessárias (conteúdos, recursos tecnológicos, práticas metodológicas, instrumentos de avaliação e/ou outras ações).

- Elaborar um cronograma, elencando as ações desenvolvidas pela U.E.

Quadro 1 - Excerto do plano de trabalho da Diretoria Gama

Tal proposta parece não se ter consolidado na maioria das diretorias regionais, visto que, em todas as diretorias visitadas, o único plano de trabalho sistematizado foi mostrado à pesquisadora foi o da Diretoria Gama, que se constituía de relatório geral sobre a situação das escolas em relação às expectativas do SARESP e plano de trabalho, tal como exemplificado no Quadro 1.

Outras diretorias declararam incorporar os dados do SARESP ao seu plano diretor, mas o fato de esses documentos não terem sido acessados durante as visitas fez com que não se tivessem evidências empíricas sobre o que foi declarado.

0 que se conclui, a partir da fala dos técnicos entrevistados, é que algumas diretorias e escolas têm começado a avaliar seu trabalho, a fazer avaliações prévias e a incorporar os resultados das avaliações em seu planejamento.

Há a dificuldade de saber como trabalhar com redação do ponto de vista coletivo, 
dentro do grupo, e que não implique só a correção de todas as redações, uma vez por semana, uma vez por mês, que acumularia muito para o professor ${ }^{12}$. Então a gente fez uma Orientação Técnica. E a primeira parte da reunião foi para que eles mesmos analisassem quais os problemas que têm com o trabalho e por que será que nós tivemos aquele resultado. Falamos que tendo em vista que o SARESP tem uma prova, baseada no tipo de redação dissertativo-argumentativa, é necessário trabalhar no $1^{\circ}$, no $2^{\circ}$, no $3^{\circ} \ldots$ "Ah, tem que trabalhar no primeiro?". Ou seja, eles não sabiam, não era claro... Porque a programação não é trabalhada com os professores. [...] Eu acho que um dos papéis do SARESP é isso mesmo: trabalhar o mínimo curricular que a escola deve oferecer para que o aluno tenha certa formação, de argumentar, de escrever, de refletir... [...] Essa coisa de correção da programação, de trabalho do professor, isso eu acho que é uma coisa boa. (Supervisor de Ensino / Coordenador do SARESP, D. E. Beta; grifos nossos)

A gente trabalha mais com resultados das escolas, chamamos os coordenadores no início do ano e a gente orienta como a escola pode estar trabalhando dentro desse resultado no planejamento porque acho que é importante no decorrer do ano para recuperação paralela. Eles pegam o resultado do SARESP, comparam com o que foi desenvolvido em sala de aula e montam-se turmas de recuperação e até sugerimos que eles montassem turmas de produção de texto. (ATP de língua portuguesa, D. E. Delta; grifos nossos)

Essa sistemática de trabalho, contudo, não pareceu estar arraigada no sistema, tendo

12- Segundo se pôde compreender, a professora está referindo-se à dificuldade que o professor enfrenta, com salas de aula numerosas, na proposição de um efetivo trabalho de redação. Um acompanhamento mais individualizado do percurso dos alunos é dificultado pela falta de tempo do professor para corrigir tantas redações. em vista que muitas diretorias e escolas continuavam desconsiderando os resultados do SARESP à época da pesquisa, apesar de ações implantadas pela Secretaria para garantir o acesso aos dados, como a criação de um mecanismo de controle do acesso dos dados à escola. Tal mecanismo, por exemplo, não tinha sido capaz de garantir uma maior incorporação dos resultados da avaliação às práticas escolares ou, ainda, às ações de formação das diretorias de ensino.

Ainda que se questione em que medida os resultados do SARESP estão sendo efetivamente utilizados na rede pública estadual, não se pode desconsiderar que ações pontuais, muitas delas bastante interessantes, têm acontecido, tanto nas escolas, quanto nas diretorias regionais. As reuniões por polos realizadas pela Diretoria Gama, as oficinas para professores da Diretoria Beta ${ }^{13}$, a busca por parceiros e a elaboração de projetos de trabalho a partir dos resultados da avaliação da Diretoria Delta ${ }^{14}$ exemplificam essa afirmação. 0 pequeno universo estudado permite inferir que tais ações dão-se pelo diferencial das diretorias e não por uma ação sistemática da Secretaria, devendo-se muito mais às capacidades individuais das equipes da Diretoria do que à política de avaliação ou a resultantes de uma sistemática de trabalho proposta pela Secretaria da Educação.

\section{Considerações adicionais à guisa de conclusão}

De modo dominante, a pesquisa evidenciou frágil articulação entre os resultados do

13- Na Diretoria Beta, observou-se que, a partir dos resultados obtidos pelos alunos do ensino médio em redação, havia uma dificuldade dos professores em ensinar a dissertação. Tais professores foram chamados à Diretoria e puderam participar de oficinas de estudo sobre aquele tipo textual, elaboradas pelos ATPs. Segundo os técnicos dessa Diretoria, esta é uma prática constante em seu trabalho. Também afirmaram que, a partir das reuniões com os professores, puderam verificar que 0 tipo de texto dissertação só era trabalhado no último ano do ensino médio e que, portanto, deveria haver uma adequação em termos curriculares para que 0 trabalho fosse iniciado em um momento anterior.

14- A Diretoria Delta, localizada em uma região mais carente da metrópole paulistana, tem procurado melhorar os resultados de suas escolas na avaliação por meio do estabelecimento de parcerias com diversas instituições que realizam atividades com os alunos e com os professores. 
SARESP e as políticas de formação no nível das diretorias de ensino.

Por meio dos depoimentos obtidos durante a pesquisa, é possível traçar, em certo sentido, um histórico sobre como esses dados vinham sendo trabalhados e para que eram utilizados, tanto na escola, quanto nas diretorias, ao longo dos dez primeiros anos do SARESP. Assim, é possível afirmar que houve um primeiro momento, na história do SARESP, em que sobre as diretorias de ensino recaía a responsabilidade de formulação e acompanhamento dos cursos de formação, quando as ações de formação docente pareciam guardar certa consonância com o trabalho das escolas e das diretorias.

Ainda na gestão de Rose Neubauer, os dados das escolas, organizados em um documento com estrutura previamente definida, eram enviados às diretorias regionais para serem analisados pelas equipes de avaliação. A partir dessa análise, as equipes das diretorias produziam relatórios ${ }^{15}$ nos quais procuravam compreender os resultados obtidos, relacionando-os às características das regiões e estabelecendo metas e diretrizes de trabalho a fim de melhorar os resultados da avaliação. Isso ocorria até os anos 2000, com o propósito de fazer a formação das equipes técnica e escolar para o entendimento e a manipulação das informações obtidas por meio da prova (BAUER, 2006).

As diretorias regionais pareciam ter um trabalho bastante aprofundado de análise, incluindo a crítica ao instrumento de avaliação, como pode ser visto em excerto do Relatório da Diretoria Alfa no ano 2000:

15- Em sua tese de doutoramento, Cristiane Machado (2003) analisou 88 relatórios produzidos pelas diretorias regionais de ensino. Ela explica a sistemática de construção desses relatórios: "Os relatórios de avaliação do processo de aplicação do SARESP das Diretorias de Ensino são baseados nas informações contidas nos relatórios de avaliação que cada escola elabora ao final da aferição. É a partir dessas informações que a equipe de supervisores, que acompanha a aplicação do SARESP, faz análises sobre os avanços e as dificuldades do trabalho pedagógico e as propostas e ações a serem desenvolvidas pelas Diretorias. É importante informarmos como se dá o processo de totalização das notas das escolas pelas Diretorias. Após a correção das provas e a digitação dos dados no programa de informática pelas escolas, as Diretorias importam esses dados para o programa de informática da Diretoria e calculam a média entre as suas escolas" (p. 134). os conteúdos das questões estão adequados aos PCNs, porém várias questões não estão de acordo com a realidade em que está inserido o aluno. (Excerto do Relatório da D. E. Alfa, 2000)

Essa etapa de construção coletiva de relatórios parece ter significado, para algumas equipes, uma possibilidade de estudo sobre sua realidade, sendo que em várias das instituições visitadas os entrevistados insistiram em mostrar esse material: "Nós levamos a sério o estudo, ele nos ajudou... Veja, até parece uma tese" (Coordenadora de Avaliação da D. E. Beta); "Eu ainda não coordenava a avaliação naquela época, mas eles faziam o relatório e era bem complexo!" (Anotações do diário de campo da pesquisadora).

Nesse sentido, a utilização dos resultados do SARESP como subsídio para a definição de políticas de formação e ações formativas realizadas na Diretoria pareceu ocorrer da forma anunciada nos documentos oficiais naquele momento.

Independentemente da efetividade formativa da produção realizada nesse primeiro momento de trabalho, nota-se que a ele seguiu-se uma orientação em que a realização desses relatórios deixou de ser demandada, e a Secretaria parece ter modificado suas intenções no que se refere ao trabalho com resultados, visto que passou a enviar às escolas dados estatísticos e mudou a sistemática de envio de resultados para as diretorias.

Como explicou uma das supervisoras de ensino entrevistadas, responsável pela Coordenação da Avaliação na Diretoria Delta, apesar de não receberem mais um relatório que apoie o trabalho a ser realizado, seria possível que a equipe fizesse análises a partir dos dados quantitativos. Mas, no momento em que a Secretaria decidiu não enviar mais os dados de cada escola para a Diretoria, foi criado um descompasso: a Diretoria de Ensino tem responsabilidade de acompanhar um trabalho de análise de dados, de auxiliar 
as escolas na definição dos melhores encaminhamentos, mas ela mesma tem dificuldade de acesso a esses dados, o que pode gerar uma dissociação entre o trabalho das escolas e o da Diretoria, como de fato aconteceu na maioria das diretorias visitadas.

Contudo, quando a avaliação assumiu um novo caráter após 2001, sendo seus resultados utilizados para a tomada de decisão sobre a vida escolar dos alunos, houve uma ruptura com o trabalho que se estava desenvolvendo até então. Esse fato parece ter rompido com os propósitos iniciais da política de avaliação e, aliado à mudança do Secretário da Educação, constituiu um marco no processo que vinha sendo instaurado, pois a mudança de Secretário foi acompanhada por novos princípios, valores e entendimentos das questões educacionais ${ }^{16}$. Assim, no segundo período da gestão de Geraldo Alckmin ${ }^{17}$, com Gabriel Chalita à frente da Secretaria da Educação, várias mudanças foram introduzidas no sistema de avaliação: este passou a ser censitário, incorporou a ideia de avaliação de habilidades e competências, e novos procedimentos estatísticos para análise dos dados foram introduzidos (BAUER, 2006).

Quanto à política de formação, a ênfase recaiu sobre a proposição de inúmeras ações que visavam à formação do professor para o trabalho com leitura e, com menos destaque, escrita. Os programas de formação tornaram-se mais centralizados e houve uma proliferação de atividades que, de acordo com os depoimentos colhidos nas diretorias, chegou até mesmo a prejudicar a dinâmica escolar por

16- 0 foco escolhido para o presente texto não permite apresentar a análise da proposta educacional desse governo a fim de ilustrar as afirmações realizadas. 0 leitor, contudo, pode encontrar evidências do exposto no trabalho original (ver BAUER, 2006).

17- Vice-Governador de São Paulo, Geraldo Alckmin assumiu o governo interinamente em 2001, quando o então Governador Mário Covas afastou-se do governo por agravamento de seu estado de saúde. Com o falecimento do Governador, Alckmin assumiu o governo do Estado, concluindo 0 mandato para o qual Covas havia sido reeleito. Alckmin venceu as eleições de 2002, dando continuidade a seu governo e tendo à frente da Secretaria da Educação o Prof. Gabriel Chalita. mobilizar vários professores ao mesmo tempo. Essa ruptura, tanto nos programas de formação quanto no de avaliação, pode ter contribuído para que a articulação anunciada entre esses programas não se concretizasse da forma como foi idealizada.

Talvez essas vicissitudes que influenciaram a política educacional no período de 2001 a 2006, quando a pesquisa foi finalizada, possam contribuir para explicar o porquê de a relação entre formação docente contínua e avaliação parecer pouco explorada pelo nível intermediário do sistema educacional (as diretorias de ensino).

Nesse sentido, por hipótese, os resultados obtidos em relação à concretização da relação avaliação/formação estariam mais relacionados às mudanças na concepção inicial da política, efetuada pelos implementadores, do que seriam resultantes de uma intencionalidade política. As poucas iniciativas em relacionar as ações formativas aos resultados do SARESP poderiam ser atribuídas às concepções dos profissionais das diretorias sobre seu papel, sobre o significado das avaliações e de seus resultados, e não serem decorrência da política em si, que não previu mecanismos efetivos que possibilitassem aos usuários dos resultados da avaliação, no nível intermediário, relacioná-la à formação.

De qualquer forma, foi possivel constatar que, a partir dos resultados do SARESP, algumas diretorias formularam ações para incidir na relação entre as práticas escolares e as habilidades e os conteúdos que compõem a matriz curricular da prova, dando à formação o sentido de treinamento, de um preparo para a execução de determinada tarefa de acordo com diretrizes previamente delimitadas.

Dentre as questões suscitadas pela pesquisa, uma das mais instigantes e que permanece a ser investigada refere-se às melhores formas de explorar os resultados produzidos pela avaliação, quer no cotidiano da sala de aula, quer como informação para a formulação e a implementação de políticas educacionais. 


\section{Referências}

AFONSO, Almerindo. Políticas educativas e avaliação educacional. Braga: Universidade do Minho, 1998.

BARRETO, Elba Siqueira de Sá; PINTO, Regina Pahim. Avaliação de programas educacionais: indagações metodológicas e disseminação de resultados. In: BARREIRA, Maria Cecília Roxo N.; CARVALHO, Maria do Carmo. B. Tendências e perspectivas na avaliação de políticas e programas sociais. São Paulo: IEE/PUC-SP, 2001. p. 101-126.

BAUER, Adriana. Uso dos resultados do SARESP: o papel da avaliação nas políticas de formação docente. Dissertação (Mestrado) - Faculdade de Educação, Universidade de São Paulo, São Paulo, 2006.

BITAR, Hélia. et al. 0 Sistema de Avaliação de Rendimento Escolar do Estado de São Paulo: implantação e continuidade. Série Idéias, São Paulo, n. 30, p. 09-20, 1998.

DIAS SOBRINHO, José. Campo e caminhos da avaliação: a avaliação da educação superior no Brasil. In: FREITAS, Luiz Carlos de (Org.). Avaliação: construindo o campo e a crítica. Florianópolis: Insular, 2002. p. 13-62.

FIGUEIRED0, Marcus Faria; FIGUEIRED0, Argelina M. Cheibub. Avaliação de políticas: um quadro de referência. Análise e Conjuntura, Belo Horizonte, v. 1, n. 3, p. 107-127, 1986.

GARCIA, Carlos M. Formação de professores principiantes. In: Formação de professores para uma mudança educativa. Porto: Porto Editora, 1999. p. 110-130.

LAVILLE, Christian; DIONNE, Jean. Em busca de informações. In: A construção do saber: manual de metodologia de pesquisa em ciências humanas. Porto Alegre: Editora Artmed; UFMG, 1999. p. 168-197.

MACHADO, Cristiane. Avaliação e política: limites e potencialidades. Tese (Doutorado) - Faculdade de Educação, Universidade de São Paulo, São Paulo, 2003.

PALUMBO, Dennis. A abordagem de política pública para o desenvolvimento político na América. In: SOUZA, Eda C. B. Machado de (Org). A avaliação e a formulação de políticas públicas em educação: leituras complementares. Brasília: MEC/UnB, 1998. p. 35-62.

SÃO PAULO (Estado). Secretaria de Estado da Educação. Comunicado SE/95. 22 mar. 1995.

SARESP 98: manual de orientação. São Paulo: Fundação para o Desenvolvimento da Educação, 1998.

VIANNA, Heraldo. Avaliações nacionais em larga escala: análises e propostas. São Paulo: FCC, 2003.

WHOLEY, Joseph S. Using evaluation to improve performance and support policy decisionmaking. In: ALKIN, M. C. Evaluation roots. Thousand Oaks: Sage, 2004. p. 267-275.

WORTHEN, Blaine; SANDERS, James; FITZPATRICK, Jody. Avaliação de programas: concepções e práticas. São Paulo: Editora Gente, 2004.

Recebido em: 16.04.2010

Aprovado em: 11.10.2010

Adriana Bauer é doutora pela Faculdade de Educação da Universidade de São Paulo e pesquisadora da Fundação Carlos Chagas. 